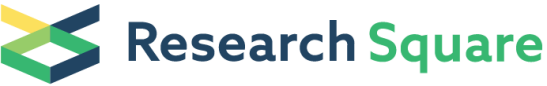 \\ Preprints are preliminary reports that have not undergone peer review. \\ They should not be considered conclusive, used to inform clinical practice, or referenced by the media as validated information.
}

\section{The Functional Characterization of Phosphorylation of Tristetraprolin at C-Terminal NOT1-binding Domain}

\section{Hsin-Hui Hsieh}

National Taiwan University of Science and Technology Graduate Institute of Digital Learning and Education

\section{Yen-An Chen}

National Taiwan University of Physical Education and Sport

Yao-Jen Chang

Graduate Institute of Biochemical Sciences

\section{Hsin-Hui Wang}

Department of Pediatrics, Taipei Veterans General Hospital

\section{Ya-Han Yu}

National Taiwan University of Science and Technology

Sheng-Wei Lin

Institute of Plant and Microbial Biology Academia Sinica

\section{Yin-Jung Huang}

Department of Pediatrics, Taipei Veterans General Hospital

\section{Steven Lin}

Institute of Biological Chemistry, Academia Sinica

Ching-Jin Chang ( $\square$ chingjin@gate.sinica.edu.tw )

Academia Sinica https://orcid.org/0000-0001-7129-8092

\section{Research}

Keywords: Tristetraprolin, phosphorylation, CNOT1, deadenylase

Posted Date: August 4th, 2020

DOl: https://doi.org/10.21203/rs.3.rs-50794/v1

License: (c) (1) This work is licensed under a Creative Commons Attribution 4.0 International License.

Read Full License 


\section{Abstract}

Backgound: Tristetraprolin (TTP) family proteins contain conserved tandem $\mathrm{CCCH}$ zinc-finger binding to AU-rich elements and C-terminal NOT1-binding domain. TTP is phosphorylated extensively in cells and its mRNA destabilization activity is regulated by protein phosphorylation.

Methods: We generated an antibody against phospho-Serine 316 located at C-terminal NOT1-binding site and examined TTP phosphorylation in LPS-stimulated RAW264.7 cells. Knockout of TTP in RAW264.7 cells using CRISPR/Cas9 gene editing was created to explore TTP functions.

Results: We demonstrated that Ser316 was phosphorylated by p90 ribosomal S6 kinase 1 (RSK1) and p38-activated protein kinase (MK2), and dephosphorylated by Protein Phosphatase 2A (PP2A). Phosphorylation-mimic mutant of S316D resulted in dissociation with CCR4-NOT deadenylase complex through weakening interaction with CNOT1. Furthermore, Ser316 and serines 52 and 178 were independently contributed to CCR4-NOT complex recruitment in the immunoprecipitation assay using phosphor-mimic mutants. In RAW264.7 macrophages, TTP was induced and Ser316 was phosphorylated through RSK1 and MK2 by LPS stimulation. Knockout of TTP resulted in TNFa mRNA increased due to mRNA stabilization. Overexpression of non-phosphorylated S316A TTP mutant can restore TTP activity and lead to TNFa mRNA decreased. GST pull-down and RNA pull-down analyses demonstrated that endogenous TTP with Ser316 phosphorylation decreased the interaction with CNOT1.

Conclusions: Our results suggest that the TTP-mediated mRNA stability is modulated by Ser316 phosphorylation to regulate the TTP interaction with CCR4-NOT deadenylase complex.

\section{Background}

Transcriptome dynamics are governed by RNA synthesis and degradation. Regulation of mRNA stability plays a central role in controlling gene expression in the vast majority of eukaryotic cells [1-4]. The mRNA stability is modulated by cis-acting elements in the $3 \otimes$ untranslated region (UTR) as well as trans-acting factors [5, 6]. The AU-rich element (ARE) is the best-studied cis-acting element in short-lived mRNA [7]. Several ARE-binding proteins have been shown to regulate mRNA turnover/decay [8], which is initiated by deadenylation via deadenylases including poly(A)-specific ribonuclease (PARN) and the polyA nuclease 2 (PAN2)-PAN3 and carbon catabolite repression (CCR4)-negative on TATA-less (NOT) complexes [9]. CCR4NOT is a highly conserved multisubunits molecular machine with an approximate molecular mass of 1 MDa that contains two deadenylases, CCR4 (also named CNOT6) and CAF1 (also named CNOT7) [10, 11]. The largest subunit of CCR4-NOT, namely CCR4-NOT1 complex subunit 1 (CNOT1), serves as a hub of protein-protein interactions [11]. Specific mRNAs can be targeted by RNA-binding proteins to recruit deadenylase complexes for mRNA degradation [12].

Tristetraprolin (TTP) is an extensively studied ARE-binding protein. There are four TTP members in rodents, and they all contain conserved tandem $\mathrm{CCCH}$ zinc finger RNA-binding domains and a conserved C-terminal NOT1-binding domain [13]. TTP was induced by lipopolysaccharide (LPS) and serve as an 
anti-inflammatory factor to inhibit cytokine expression such as TNFa [14]. TTP family proteins are serine/threonine-rich, and they appear as multiple bands in SDS-PAGE, indicating that they are highly phosphorylated $[15,16]$. TTP can be phosphorylated by mitogen-activated protein kinase (MAPK) p38activated protein kinase 2 (MK2) at serines 52 and 178 in mouse macrophages to allow binding of 14-3-3 adaptor proteins, which inhibits the mRNA destabilizing activity of TTP $[17,18]$. In contrast, PP2A can compete with 14-3-3 proteins to dephosphorylate TTP at S178 and thereby activate decay of cellular mRNAs $[19,20]$. [15, 21]. The substitution of these two serines (S52 and S178) to non-phosphorylated alanines in the endogenous murine locus encoding TTP gave rise to a strong and dominant hypoinflammatory phenotype [22]. One molecular mechanism for TTP-mediated mRNA decay is recruitment of the CCR4-NOT deadenylase complex through direct interaction with CNOT1, resulting in decay of ARE-containing mRNAs [23, 24]. TTP phosphorylated by MK2 inhibits the deadenylase recruitment due to association with 14-3-3 [25, 26]. In addition to p38-MK2 pathway, ERK signaling has been reported to regulate protein stability, subcellular localization and function of TTP $[27,28]$.

In this study, we generate a specific antibody against phosphor- Ser316 of TTP to examine the Ser316 phosphorylation under LPS stimulation in mouse RAW264.7 macrophasges. The phosphorylation would inhibit CCR4-NOT complex recruitment and lead to inactivation of TTP mRNA destabilization activity.

\section{Materials And Methods}

\section{Cell culture}

Human embryonic kidney (HEK) 293T cells were cultured in DMEM containing $3.7 \mathrm{~g} / \mathrm{l}$ sodium bicarbonate and supplemented with 10\% FBS (Gibco-BRL), $100 \mathrm{U} / \mathrm{ml}$ penicillin, and $100 \mathrm{mg} / \mathrm{ml}$ streptomycin (Gibco-BRL) in a $5 \% \mathrm{CO}_{2}$ humidified atmosphere $\left(37^{\circ} \mathrm{C}\right)$. Mouse RAW264.7 macrophages were cultured in Roswell Park Memorial Institute (RPMI) 1640 supplemented with 10\% FBS (Gibco-BRL), $100 \mathrm{U} / \mathrm{ml}$ penicillin, and $100 \mathrm{mg} / \mathrm{ml}$ streptomycin (Gibco-BRL) in a 5\% CO2 humidified atmosphere $\left(37^{\circ} \mathrm{C}\right)$.

\section{Plasmid constructs}

The plasmids for TTP, Zfp36l1, Zfp36l2 and 14-3-3Z expression were constructed as described [15, 16, 21, 29]. The TTP mutants S 316 and S318, S52 and S178 were created by PCR (for S316 and S318) or Q5 site-directed mutagenesis kit (New England Biolabs) (for S52 and S178) using the primers indicated in Table S1. The PCR products were ligated to pCMV-Tag2 (Stratagene) and pEGFP-C2 (Clontech) for mammalian cell expression. Mouse Cnot1@800-1310 were PCR amplified from a cDNA template (OriGene) with the primers: 5'-CAGGCTCAGGCCCAGGTT-3' and 5'-TTATTAGGCCTGAGCCAGTGCAATAC-3'. The PCR products were cloned into pGEX4T-1 for expression of glutathione S-transferase (GST)-fused proteins in bacteria. 
Total RNA was extracted from cell cultures using TRIzol reagent (Invitrogen). For mRNA stability analysis, the cells were treated with $10 \mu \mathrm{g} / \mathrm{ml}$ actinomycin D (transcription inhibitor) for various times to inhibit new transcription. After DNase I digestion, $2 \mu \mathrm{g}$ total RNA was reverse-transcribed to produce cDNA using M-MLV reverse transcriptase and oligo dT primer (Promega). Real-time PCR was performed with the 7300 Real-Time PCR System (Applied Biosystems) in a total volume of $20 \mu \mathrm{l}$. Expression of genes encoding TTP, TNFa and actin was assessed using SYBR Green PCR Master Mix (Applied Biosystems) with $50 \mathrm{ng}$ of CDNA and $160 \mathrm{nM}$ of each primer: 5囚-GGATCTCTCTGCCATCTACGA-3囚 and 5》-

CAGTCAGGCGAGAGGTGAC-3囚 for TTP; 5'-GACCCTCACACTCAGATCATCTTCT-3' and 5'CCTCCACTTGGTGGTTTGCT-3' for TNFa; 5囚-TCCTTCCTGGGCATGGAGTC-3》 and 5》-

ACTCATCATACTCCTGCTTG-3\ for $\beta$-actin. The PCR amplification conditions were 40 cycles of $95^{\circ} \mathrm{C}$ for $15 \mathrm{~s}$ and $60^{\circ} \mathrm{C}$ for $1 \mathrm{~min}$. Real-time PCR data were analyzed using the $2^{-\mathrm{CT}}$ relative quantitation method.

\section{Cell extracts preparation, co-immunoprecipitation (IP), and western blotting}

293T cells were cotransfected with the plasmids using Turbofect reagent (Thermo). Cells harvested $24 \mathrm{~h}$ after transfection were lysed with NET buffer (50 mM Tris, pH 7.5; $150 \mathrm{mM} \mathrm{NaCl} ; 1 \mathrm{mM}$ EDTA; $0.1 \%(\mathrm{v} / \mathrm{v})$ Triton X-100) containing a protease inhibitor cocktail (Sigma-Aldrich) and phosphatase inhibitors (10 mM B-glycerol phosphate; $0.1 \mathrm{mM} \mathrm{Na}_{2} \mathrm{MoO}_{4} ; 0.1 \mathrm{mM} \mathrm{Na}_{3} \mathrm{VO}_{4}, \mathrm{pH} 10.0 ; 10 \mathrm{mM} \mathrm{NaF}$ ) and centrifuged at $15,000 \times g$ for $10 \mathrm{~min}$. The supernatants were immunoprecipitated using anti-Flag M2 agarose (SigmaAldrich) at $4^{\circ} \mathrm{C}$ for $2 \mathrm{~h}$. After the IP mixture was washed three times with NET buffer, bound proteins were eluted by boiling in SDS-PAGE sample buffer. The proteins were separated by SDS-PAGE $(10 \%$ polyacrylamide) and transferred to a polyvinylidene difluoride membrane (Millipore), and western blotting was performed using anti-Flag (Sigma-Aldrich), anti-HA (Bethyl), anti-TTP (produced in our lab), anti-atubulin, anti- $\beta$-actin, anti-phospho-ERK1/2, anti-p38, anti-phosph-p38, anti-MK2, anti-phospho-MK2, antiphospho-RSK1, anti-CNOT3 and anti-CNOT6 (all from Cell signaling), anti-GAPDH, anri-CNOT1, and antiCNOT7 (all from Proteintech Group), anti-ERK1/2 and anti-RSK1 (both from Santa Cruz Biotechnology), and anti-DDX6 (abcam). All experiments were carried out at least three times, and represented results were displayed.

\section{Generation of rabbit anti-phospho-S316 of TTP}

A peptide containing the sequence surrounding phospho-S316 of TTP (RLPIFNRIpSVSE) was synthesized and purified. A specific rabbit antiserum was produced by LTK BioLaboratories (Taiwan). The antiserum was affinity purified using the immunizing peptide (LTK BioLaboratories).

\section{In vitro kinase assay}

Each reaction mixture contained $2 \mu \mathrm{g}$ of recombinant GST-tagged TTP (wild type or mutants) served as substrates, $3 \mu$ of 10X reaction buffer (New England Biolabs), $30 \mu \mathrm{M}$ of ATP, and kinases including ERK2 (New England Biolabs), p38 alpha (SignalChem), RSK1 (SignalChem), and MK2 (SignalChem) in a final volume of $30 \mu \mathrm{l}$. The kinases can be from cell extracts. $300 \mathrm{~g}$ of LPS-treated RAW264.7 whole cell extracts were incubated with GSH-Sepharose bound 2 g of GST-TTP in the buffer containing $20 \mathrm{mM}$ 
HEPES, pH7.7, $75 \mathrm{mM} \mathrm{NaCl}, 0.5 \mathrm{mM} \mathrm{MgCl}_{2}, 0.1 \mathrm{mM}$ EDTA, 0.05\% Triton X-100, $0.5 \mathrm{mM}$ DTT, $20 \mathrm{mM}$ \-

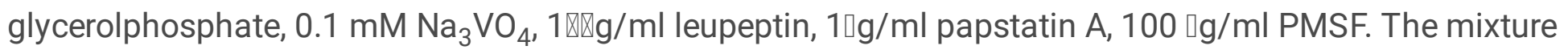
was rotated at $4^{\circ} \mathrm{C}$ for $3 \mathrm{hr}$ and pelleted by centrifigation at 10,000xg for $20 \mathrm{sec}$. After $4 \times 1-\mathrm{ml}$ washes in HEPES binding buffer (20 mM HEPES, pH7.7, $50 \mathrm{mM} \mathrm{NaCl}, 2.5 \mathrm{mM} \mathrm{MgCl}, 0.1 \mathrm{mM}$ EDTA, $0.05 \%$ Triton X100 ), the beads were resuspended in $30 \mathrm{ll}$ for kinase assay. The reaction mixtures were incubated at $30^{\circ} \mathrm{C}$ for 30 minutes and stopped by adding one volume of protein sample buffer. Samples were subjected to SDS-PAGE for western blotting with anti-phospho-S316 and ponceau S staining.

\section{GST pull-down assays}

Glutathione-Sepharose 4B ( 8 $\mu \mathrm{l}$, GE Healthcare Life Sciences) were incubated with $2 \mu \mathrm{g}$ of bacterially expressed GST, or GST-Cnot1@800-1015 or GST-14-3-3 in phosphate-buffered saline containing 1\% (v/v) Triton X-100 on a rotary shaker for $20 \mathrm{~min}$ at room temperature. After washing three times with the same buffer, the Sepharose was combined with lysates (300 $\mu$ g protein) of RAW264.7 cells that had undergone various treatments in a final volume of $200 \mu \mathrm{l}$ of buffer containing $20 \mathrm{mM} \mathrm{HEPES}, \mathrm{pH} 7.9,100 \mathrm{mM} \mathrm{NaCl}$, $2.5 \mathrm{mM} \mathrm{MgCl}_{2}, 0.1 \mathrm{mM}$ EDTA, $0.05 \%$ (v/v) NP-40, 1\% (v/v) Triton X-100, 1 mM DTT, and $1 \mathrm{mM}$ PMSF. The mixtures were incubated at $4^{\circ} \mathrm{C}$ for $2 \mathrm{~h}$ on a rotary shaker, and then the Sepharose was washed four times with the same buffer lacking DTT and PMSF but containing $0.2 \mathrm{M} \mathrm{NaCl}$ and once with $50 \mathrm{mM}$ Tris, $\mathrm{pH}$ 6.8. Bound proteins were eluted by boiling in SDS-PAGE sample buffer and analyzed by western blotting.

\section{RNA pull-down assays}

Cytoplasmic extracts from LPS-stimulated RAW264.7 cells were prepared by hypotonic buffer (10 mM HEPES, pH 7.5, $10 \mathrm{mM}$ potassium acetate, $1.5 \mathrm{mM}$ magnesium acetate, $2.5 \mathrm{mM}$ DTT, 0.05\% NP-40, and protease inhibitor cocktails). Potassium acetate was adjusted to $90 \mathrm{mM}$, and $0.1 \mathrm{U} \cdot \mu \mathrm{L}^{-1} \mathrm{RNasin}$ (Promega, Madison, $\mathrm{WI}$ ) and $20 \mu \mathrm{g} \cdot \mu \mathrm{L}^{-1}$ yeast tRNA were added to each lysate. To prevent non-specific binding, heparin-agarose (Sigma-Aldrich) was incubated with each lysate for $15 \mathrm{~min}$ at $4^{\circ} \mathrm{C}$ and then centrifuged for $1 \mathrm{~min}$ at $8,000 \mathrm{rpm}, 4^{\circ} \mathrm{C}$. Each supernatant was further cleaned with streptavidinSepharose ( $8 \mu \mathrm{L}$; Invitrogen) for $1 \mathrm{~h}$ at $4^{\circ} \mathrm{C}$ and then centrifuged for $1 \mathrm{~min}$ at $8,000 \mathrm{rpm}, 4^{\circ} \mathrm{C}$. The biotinlabeled TNFa ARE was added as described [21]. The pulled-down RNA-protein complexes were washed four times with binding buffer (hypotonic buffer containing $90 \mathrm{mM}$ potassium acetate) and separated by SDS-PAGE (10\% acrylamide) for western blotting analysis.

\section{siRNA-mediated knockdown, transfection and immunoprecipitation assay}

HEK293T cells $\left(1 \mathrm{Q} 10^{5}\right)$ were seeded in each well of a 12-well plastic culture plate. For gene knockdown, the cells were transfected with $5 \mathrm{nM}$ of a small interfering RNA (siRNA) for CNOT1, CNOT6, CNOT7, RSK1 or MK2 (Invitrogen) using Lipofectamine 3000 (Invitrogen). After $24 \mathrm{~h}$, the cells were transferred into fresh medium and transfected with $1 \mu \mathrm{g}$ of Flag-TTP wild-type, -TTP S52,178A or -TTP S316A expression plasmids using Turbofect reagent (Thermo). After another $24 \mathrm{~h}$, cells were harvested, and whole cell extracts were isolated for western blotting or immunoprecipitation. 


\section{CRISPR/Cas9-mediated gene editing}

CRISPR-based sgRNAs were designed on Benchling (https://benchling.com) and CHOPCHOP (http://chopchop.cbu.uib.no/) to search the specific target-sequences of Cas9 RNP complexes on mouse Ttp gene. Based on the description of target score [30] (http://crispr.mit.edu/about), we designed four sgRNAs, which contain a relatively higher on-target with a lower off-target score (Table 3 ) . Each DNA template of Ttp sgRNA encoding for a T7 promoter, a 20 nt target sequence and a published sgRNA scaffold [31] were assembled by overlapping PCR. Each PCR reactions contain $20 \mathrm{nM}$ premix of TTP sgRNAs and bottom scaffold (Table S2), $1 \mu \mathrm{M}$ premix of T7 oligo primer and sgRNA-reverse, $200 \mu \mathrm{M}$ dNTP and Q5 polymerase (NEB) according to manufacturer's protocol. The thermocycler setting consisted of 30 cycles of $95^{\circ} \mathrm{C}$ for 10 seconds, $59^{\circ} \mathrm{C}$ for 10 seconds and $72^{\circ} \mathrm{C}$ for 10 seconds. [32].

The assembled PCR products were extracted once with phenol:chloroform:isoamylalcohol and then once with chloroform, before isopropanol precipitation overnight at $-20^{\circ} \mathrm{C}$. The DNA pellet was washed three times with $70 \%$ ethanol and dissolved in DEPC-treated water. The T7 in vitro transcription reaction consisted of $30 \mathrm{mM}$ Tris- $\mathrm{HCl}$ (pH 7.9), $20 \mathrm{mM} \mathrm{MgCl}_{2}, 0.01 \%$ Triton X-100, $2 \mathrm{mM}$ spermidine, $10 \mathrm{mM}$ DTT, $5 \mathrm{mM}$ of ribonucleotide triphosphate, $100 \mu \mathrm{g} / \mathrm{ml}$ T7 polymerase and $1 \mu \mathrm{M}$ DNA templates. The reaction was incubated at $37^{\circ} \mathrm{C}$ for $4 \mathrm{hr}$, and RNase-free DNase was added to digest the DNA template $37^{\circ} \mathrm{C}$ for 1 $\mathrm{hr}$. The reaction was stopped by adding 2 xSTOP solution (95\% deionized formamide, $0.05 \%$ bromophenol blue and $20 \mathrm{mM}$ EDTA) at $60^{\circ} \mathrm{C}$ for $5 \mathrm{~min}$. The RNA was purified by electrophoresis in $10 \%$ polyacrylamide gel containing $6 \mathrm{M}$ urea. The RNA band was excised from the gel, grinded up in a 15-ml tube, and eluted with $5 \mathrm{vol}$ of $300 \mathrm{mM}$ sodium acetate $(\mathrm{pH} 5)$ overnight at $4^{\circ} \mathrm{C}$. One equivalent of isopropanol was added to precipitate the RNA at $-20^{\circ} \mathrm{C}$. The RNA pellet was centrifuged and washed three times with $70 \%$ ethanol, and dried by vacuum. To refold the sgRNA, the RNA pellet was first dissolved in $20 \mathrm{mM}$ HEPES ( $\mathrm{pH}$ 7.5), $150 \mathrm{mM} \mathrm{KCl,} \mathrm{10 \%} \mathrm{glycerol} \mathrm{and} 1 \mathrm{mM}$ TCEP. The sgRNA was heated to $70^{\circ} \mathrm{C}$ for $5 \mathrm{~min}$ and cooled to room temperature. $\mathrm{MgCl}_{2}$ was added to a final concentration of $1 \mathrm{mM}$. The sgRNA was again heated to $50^{\circ} \mathrm{C}$ for $5 \mathrm{~min}$, cooled to room temperature and kept on ice. The sgRNA concentration was determined by $\mathrm{OD}_{260 \mathrm{~nm}}$ and adjusted to $100 \mu \mathrm{M}$ using $20 \mathrm{mM}$ HEPES (pH 7.5), 150 $\mathrm{mM} \mathrm{KCl}, 10 \%$ glycerol, $1 \mathrm{mM} \mathrm{TCEP}$ and $1 \mathrm{mM} \mathrm{MgCl}_{2}$. The sgRNA was store at $-80^{\circ} \mathrm{C}$ [32].

Transfection of RAW264.7 cells were performed according to the instructions of Lipofectamine ${ }^{\mathrm{TM}}$ CRISPRMAX ${ }^{\mathrm{TM}}$ Cas 9 Transfection Reagent (Invitrogen). The Cas9 RNP were prepared by incubating the purified Cas 9 protein with sgRNA at $1: 4$ molar ratios. After transfection, the cells were incubated at $37^{\circ} \mathrm{C}$ for $48 \mathrm{hr}$, and followed by single cell sorting using BD, FACSJazz automated cell sorter to perform the single isolation. (TechComm at NTU)

\section{Genomic DNA isolation and PCR analysis}

Genomic DNA was extracted by QuickExtract ${ }^{\mathrm{TM}}$ DNA Extraction Solution (epicentre). Cells were mixed by $200 \mu \mathrm{l}$ of QuickExtract Solution and vortex for 15 seconds. The tubes were transferred to $65^{\circ} \mathrm{C}$ and incubate for 6 minutes. After 15 seconds vortex, samples were incubated at $98^{\circ} \mathrm{C}$ for 2 minutes. Store the 
DNA at $-20^{\circ} \mathrm{C}$, or at $-80^{\circ} \mathrm{C}$ for long term storage according to manufacturer's protocol. Genomic DNA were PCR amplified using primer-1 and primer-4 (Table S2). Theoretically, sgRNA mTTP KO-1 and sgRNA mTTP KO-4 will generate double-stand DNA break on each of the target site, and cause a $793 \mathrm{nt}$ deletion between exon 1 and exon 2 on Ttp gene in RAW264.7 cells. Therefore, the size of PCR product generated by primer-1 and primer- 4 will be reduced from 2001 nt to 1208 nt. Besides, primer-2 and primer-3 locate on the predicted cutting fragment. If the TTP knock-out happened, it would not have PCR products between primer- 1 and primer-2 or primer-3 and primer-4 by theoretically (Table S2).

\section{Statistical analysis}

All data are presented as the mean \pm SD of at least three independent experiments. Statistical significance $\left({ }^{\star} P<0.05,{ }^{\star} P<0.01\right.$ or $\left.{ }^{\star * \star} P<0.001\right)$ was determined by one-tailed Student's $t$-test.

\section{Results}

\section{Serine 316 of TTP is phosphorylated by RSK1 and MK2}

Ser316 is located in the C-terminal conserved region of TTP family proteins, and this region is critical for CCR4-NOT complex recruitment $[13,23,33]$. To detect Ser316 phosphorylation in physiological conditions, a specific antibody against phospho-Ser316 was generated, and its specificity was established using wild-type or mutant TTP (Fig.1A). The signals were disappeared after treated with calfintestinal alkaline phosphatase, suggesting this antibody was phosphor-specific. Although TTP family proteins such as Zfp36l1 and Zfp36I2 have conserved NOT1-binding domain, this anti-phospho-Ser316 specifically recognized TTP but not Zfp36l1 and Zfp36l2 (Fig.1B). Enhancing either ERK or p38 signaling pathways by overexpression of MKK1 or MKK3 respectively increased Ser316 phosphorylation (Fig.S1A). The sequence of Ser316 is similar to the consensus sequence recognized by protein kinase $A, G$ and $C$ family [34]. The ERK downstream kinase RSK and p38 downstream kinase MK2 belong to this family. In vitro kinase analysis combined with western blotting showed that recombinant RSK1 and MK2 but not ERK2 and p38 can phosphorylate GST-TTP at Ser316 (Fig.1C). Knockdown of MK2 and RSK1 by using siRNA in 293T cells decreased Ser316 phosphorylation in overexpression of wild-type and S52,178A mutant (Fig.1D). Serines 52 and 178 of TTP have known to be phosphorylated by MK2 [18], and our result showed that Ser316 is an another MK2-phosphorylated residue. The Ser316 phosphorylation was decreased under overexpression of wild-type PP2A (Fig.S1B), indicating PP2A dephosphorylates Ser316 phosphorylation. Taken together, we generate a specific antibody against Ser316 of TTP and demonstrate that Ser316 can be phosphorylated by MK2 and RSK1 and dephosphorylated by PP2A.

\section{Ser316 phosphorylation prevents TTP interaction with CCR4-NOT deadenylase complex}

To explore the effect of Ser316 phosphorylation, IP was performed to examine the interaction between TTP mutants and the CCR4-NOT complex. Compared to wild-type and non-phosphorylated S316,318A mutant, the S316,318D phosphomimic mutant weakened associations with CNOT1, CNOT3, CNOT6 and CNOT7 (Fig. 2A). The single mutant of S316D but not S318D decreased interaction with CNOT1(Fig.S2A) 
and also decreased the suppressive activity of TTP on ARE-mediated luciferase analysis (Fig.S2B), indicating S316 phosphorylation plays function in CCR4-NOT complex-mediated RNA decay. When CNOT1 was knocked down, TTP could not associate with CNOT6 and CNOT7 in the co-IP experiments (Fig. 2B). In CNOT7-knockdown cells, the precipitated CNOT6 was less abundant than in control cells (Fig. 2B). These results suggest that TTP interacts with CNOT1 directly to recruit the CNOT6 and CNOT7 deadenylases, and the recruitment of CNOT6 is dependent on CNOT7. The knockdown of CNOT1 showed stronger effect in perturbing TTP function than knockdown of CNOT6 or CNOT7 (Fig.S2C). It is known that MK2 phosphorylates mouse TTP majorly at Ser52 and Ser178 and creates a functional 14-3-3 binding site and further prevents deadenylase complex recruitment $[17,18,26]$, and Ser316 is a minor MK2-phosphorylated residue [17]. We would like to compare the CCR4-NOT complex recruitment activity between the mutants of both residues of serines 52 and 178 and Ser316. As shown in Fig.2C, phosphomimic mutants of S316D and S52,178D exhibited poor association with CNOT1 and three residues mutant of S52,178, 316D totally lost the interaction with CCR4-NOT complex. When treated with PP2A inhibitor okadaic acid (OA) to activate $\mathrm{p} 38$ and ERKs signaling pathways, TTP was highly mobility-shifted as hyper-phosphorylated including phosphorylated at Ser316 (Fig.2D). Under this condition, not only wildtype TTP decreased interaction with CCR4-NOT complex but also mutants of S316A and S52, 178A did. These results imply that TTP phosphorylation at either serines 52 and 178 or at Ser316 independently decreases CCR4-NOT deadenylase complex recruitment.

\section{Ser316 of TTP is phosphorylated in LPS-stimulated RAW264.7}

To investigate the functional effect of Ser316 phosphorylation, we examine it in LPS-stimulated RAW264.7 macrophages. As shown in Fig.3A, LPS induced TTP expression and Ser316 phosphorylation. RSK1 and MK2 also were activated in early LPS stimulation (Fig.3B). When RSK1 or MK2 inhibitor was pre-treated for 30 min followed by LPS stimulation for $1 \mathrm{~h}$, Ser316 phosphorylation was slightly decreased and the typical TTP target mRNA TNFa was suppressed in the presence of RSK1 inhibitor (Fig.3C). However, the kinase inhibitors treatment showed no significant effect on TNFa mRNA stability analysis by addition of transcription inhibitor actinomycin D (Fig.S3). The solid phase kinase assays demonstrated that LPS stimulation for 30 min induced Ser316 phosphorylation (Fig.3D). Taken together, Ser316 of TTP is phosphorylated in LPS-stimulated RAW264.7 cells and RSK1 and MK2 might involve this residue's phosphorylation.

\section{Generation of TTP knockout RAW264.7 cells using CRISPR/Cas9 genome editing}

TTP is highly induced under LPS stimulation to destabilize some cytokines mRNA [35]. We are interested in the functional role of Ser316 phosphorylation on mRNA stabilization. At first, we created TTP knockout (KO) RAW264.7 macrophages using CRISPR-Cas9 genome editing. We induced two double strain breaks to remove the TTP exon fragment in RAW264.7 genomes (Fig. S4A). Four sgRNAs (single-guide RNAs) (sequences showed in Table S2) were designed by Benchling (https://benchling.com/) to recognize the TTP sequence on mouse genome and were in vitro transcribed (Fig. S4B). Cas9 protein and sgRNAs were prepared and co-transfected into RAW264.7 cell. The combination of sgRNA-1 and sgRNA-4 had the most 
cutting efficiency which was checked by genomic PCR (Fig.S4C). By flow cytometry and cell sorting, RAW264.7 cells were separated into single cell for the selection. Homozygous and heterozygous TTP KO cell lines were identified by genomic PCR (Fig. S4D). Further check of genomic PCR was designed by using three pairs of primer to demonstrate TTP KO cell lines (Fig. 4A). The qPCR and western blotting assays were performed to confirm no TTP mRNA and protein expression in KO cells (Fig.4B). TTP KO RAW264.7 cells are used to examine the functional effects of phosphorylated mutants.

\section{The functional effect of Ser316 phosphorylation in LPS-stimulated RAW264.7 cells}

The qPCR analysis showed the TNFa mRNA expression levels in wild-type and TTP KO cells (Fig.5A). Interestingly, TNFa mRNA was induced at $30 \mathrm{~min}$ and then decreased at $1 \mathrm{~h}$ in wild-type cells, while no decrease of TNFa at $1 \mathrm{~h}$ induction in TTP KO cells. The mRNA stability was analyzed by adding the transcription inhibitor actinomycin $\mathrm{D}$ at $30 \mathrm{~min}$ (Fig.5B). The longer mRNA half-life was observed in TTP $\mathrm{KO}$ cells. It indicates that TTP plays a role in the TNFa mRNA decay. To investigate how Ser316 phosphorylation affect TNFa mRNA stability, the KO cells were transfected with plasmids expressed EGFP-TTP(S316A) or EGFP-TTP(S316D) or EGFP vector control. After transfection, the cells were treated with LPS to induce TNFa expression and RNA was isolated for qPCR analysis (Fig.5C). In the presence of TTP (S316A) the TNFa's induction was decreased, indicating the higher suppressive activity of nonphosphorylated mutant S316A than phosphomimic S316D. The results indicate that Ser316 phosphorylation of TTP decreases its mRNA destabilization activity.

\section{The molecular mechanism of Ser316 phosphorylation-regulated mRNA expression}

The C-terminal domain of TTP is required for Ccr4-Not complex recruitment through direct interaction with NOT1[23]. To further explore the functional regulation of LPS-stimulated Ser316 phosphorylation, GST pull-down was performed by using GST-14-3-3 or GST-Cnot1@800-1310 to pull-down LPS-treated RAW264.7 cell extracts (Fig.6A). Interestingly, the TTP pulled down by GST-Cnot1 was not recognized by anti-phospho-Ser316; however, pulled down by GST-14-3-3 exhibited high molecular weight and was detected by anti-p-Ser316. Moreover, we performed RNA pull-down assay using TNFa ARE incubating with LPS-treated cell extracts (Fig.6B). TTP with Ser316 phosphorylation can be pulled-down by TNFa ARE; however, the Cnot1 was not detected in the pull-down reactions of LPS-stimulated for $1 \mathrm{~h}$ and $2 \mathrm{~h}$. These suggest that Ser316 phosphorylation does not alter RNA-binding activity of TTP, but weakens Cnot1 interaction and enhances 14-3-3 interaction. In addition, TTP is a nucleo-cytoplasmic shuttling protein whose localization is controlled by external stimuli [36]. To further demonstrate the relationship of TTP phosphorylation and the subcellular localization, NIH3T3 cells were transfected with GFP-fused proteins for indirect immunofluorescence staining. As shown in Fig.6C, all wild-type, S316A and S316D mutants were predominantly located in cytoplasm and showed the similar colocalization with p-body marker DDX6. When cells treated with leptomycin B (LMB) which blocks exportin 1-mediated TTP protein export [37], TTP was majorly in nucleus, suggesting its nucleocytoplasmic shuttling property. The quantified result exhibited that the ratio of nucleus and cytoplasm in S316D phospho-mimic mutant was lower than 
wild-type and S316A mutant, indicating phosphorylation at Ser-316 slightly inhibited TTP nuclear import (Fig.6C). Taken together, TTP might retain in cytoplasm when Ser316 is phosphorylation.

\section{Discussion}

TTP is a highly phosphorylated protein and the functional regulation by phosphorylation is an important subject in TTP study [38-40]. We generated a specific antibody against phospho-Ser316 and demonstrated that ERK-RSK1 and p38-MK2 signaling pathways phosphorylate TTP at Ser316 in LPSstimulated RAW264.7 cells (Fig.1 and Fig.3). It further confirms that TTP-mediated turnover of TNF-a mRNA is inhibited by the combined activation of ERKs and p38 [28]. Our finding suggests that a single residue might be phosphorylated temporally by a distinct kinase in response to differential signals. Previously, Ser316 phosphorylation was observed by mass spectrometry analysis in both in vitro phosphorylation of MK2 and LPS-stimulated RAW264.7 macrophages [22]. However, its functional significance was not investigated yet. The IP, GST pull-down, and RNA pull-down assays (Fig.2 and Fig.6) demonstrated that Ser316 phosphorylation weakens the interaction with CNOT1 in CCR4-NOT deadenylase complex. It was consistent with a report described that the human TTP peptide (residues 312-326, mouse TTP residues 305-319) containing phospho-S323 (like mouse S316) showed lower CNOT1@800-999 binding affinity than the wild-type peptide [23]. Additionally, the ERK-RSK pathway also phosphorylates one of the TTP family proteins, ZFP36L1, at S334 in the conserved C-terminal NOT1binding domain and inhibits its interaction with CNOT7 [33]. We also provide evidence to prove the Ser316 phosphorylation was removed by PP2A (Fig.S1B).

CNOT1 is a scaffold protein that interacts with the deadenylase CNOT7 via its central MIF4G domain [41], with CNOT9 via a DUF3819 domain [42, 43], with the CNOT2-CNOT3 heterodimer via a C-terminal SH domain [44, 45], and with CNOT10-CNOT11 via its N-terminus [46]. CNOT6 interacts with CNOT7 via its Nterminal leucine-rich repeat domain, but it does not interact directly with CNOT1 [47]. IP showed that TTP forms a complex with CNOT1, CNOT3, CNOT6, and CNOT7 (Fig. 2A). When we used tandem mass spectrometry to analyze TTP-associated proteins, several CCR4-NOT complex subunits were detected, including CNOT1, CNOT2, CNOT6, CNOT6L, CNOT10, and CNOT11 (data not shown). Knockdown analyses demonstrated that CNOT1, CNOT6, and CNOT7 play roles in TTP mRNA destabilization activity (Fig. 2B and Fig.S2). When CNOT1 was knocked down, CNOT6 and CNOT7 could not be coprecipitated with TTP (Fig. 2B). Therefore, knockdown of CNOT1 had a greater effect on TTP activity than knockdown of CNOT6 or CNOT7 (Fig.S2C). Through the interaction with CNOT1, TTP might communicate with other components of the mRNA decay machinery. The MIF4G domain of CNOT1 also interacts with the translation repressor DDX6 to bridge deadenylation and decapping $[42,43,48]$. Recent studies have shown that CNOT9 interacts with GW182/TNRC6C and involves in microRNA-mediated repression [42, 43]. However, in our immunofluorescence staining and IP results (Fig.2C), the interaction between TTP and DDX6 is phosphorylation independent. TTP might associate with DDX6-containing P-body in RAW264.7 cells [49]. 
In response to LPS stimulation, the TNFa mRNA was dramatically induced at 30 min and decreased at 1 $\mathrm{h}$ (Fig.5A), while the decrease was not observed in TTP KO cells, indicating TTP plays a role in this response. When ectopic expression of TTP S316A or TTP S316D in TTO KO cells, the decrease at $1 \mathrm{~h}$ was not recovered (Fig.5C). We suggest that the dynamic TTP phosphorylation is required for the bi-phasic TNFa expression [50, 51], and the lower amount and hypo-phosphorylated TTP at $1 \mathrm{~h}$ induction (Fig.4A) exhibits higher mRNA destabilization activity. Like phosphorylation at serines 52 and 178 by p38-MK2 [27], Ser316 phosphorylation of TTP also displayed cytoplasmic localization (Fig.6C). It might be due to the interaction between hyper-phosphorylated TTP and 14-3-3 protein (Fig.6A). We observed serines 52 and 178 and Ser316 played functions independently in the recruitment of CCR4-NOT deadenylase complex. That is TTP phosphorylation on either Ser52,178 or Ser316 would decrease association with CCR4-NOT complex (Fig.2D). TTP contains intrinsically disordered regions (IDRs) which facilitates rapid degradation of TTP protein [52]. The serines 52 and 178 are located in IDR, and those phosphorylations can inhibit TTP protein degradation [27, 51]. Ross and his colleagues generated the mouse strain expressed TTP-S52,178A, and the mutant protein was unstable and expressed low levels in mice, but it functioned higher mRNA destabilization activity than wild-type [22]. TTP-S316A or -S316D mutants did not alter their protein half-lives in our preliminary examination. Our results imply the complex regulation of TTP phosphorylation, which might control a network of protein-protein interaction to modulate target mRNA stability.

\section{Abbreviations}

ARE: Au-rich element; Caf1: Ccr4-associated factor 1; Ccr4: Carbohydrate catabolism repression 4; CRISPR/Cas9: clustered regularly interspaced short palindromic repeats/CRISPR-associated protein nuclease; MAPK: mitogen-activated protein kinase; ERK: extracellular signal-regulated kinase; GST: Glutathione S-transferase; IL: Interleukin; IP: immunoprecipitation; LPS: lipopolysaccharide; MK2: MAPKactivated kinase 2; NOT1: Negative on TATA 1; PP2A: protein phosphatase 2A; RSK1: p90 ribosomal S6 kinase 1; sgRNA: single-guide RNA; TNF: Tumor necrosis factor; TTP: Tristetraprolin; UTR: untranslated region; Zfp36l1: Zinc finger protein 36, C3H type-like 1.

\section{Declarations}

\section{Acknowledgements}

We thank Drs. Natalie G. Ahn (University of Colorado), and Dr. Sheng-Chung Lee (National Taiwan University) for providing plasmids, Drs. Chi-Chi Chou and Shu-Yu Lin (Academia Sinica) for mass spectrometry analysis, Yi- Fan Chen for technical support and the Biotech Center of National Taiwan University for DNA sequencing. This work was supported by Academia Sinica grant 034004 (to C.J. Chang), and Ministry of Science and Technology grants 107-2314-B-075 -036- and 108-2314-B-075 -043 MY2 (to H.H. Wang), and Taipei Veterans General Hospital Grants V105C-179, V106C-180 and V107C-176 (to H.H. Wang). 


\section{Conflict of interest}

The authors declare that they have no conflicts of interest with the contents of this article.

\section{Author contribution}

$\mathrm{HHH}$ designed, performed and analyzed most figures. YAC and YJC performed CRISPR/Cas9 genome editing. HHW and SL provided studying materials and technical support. YHY performed Figure 3 and Figure $6 \mathrm{~A}$ and $6 \mathrm{C}$. SWL expressed and purified recombinant GST-fused proteins. YJH performed Figure 5A and $5 \mathrm{C}$. CJC conceived and coordinated the study and wrote the paper.

\section{References}

1. Hao, S. \& Baltimore, D. (2009) The stability of mRNA influences the temporal order of the induction of genes encoding inflammatory molecules, Nat Immunol. 10, 281-8.

2. Cheadle, C., Fan, J., Cho-Chung, Y. S., Werner, T., Ray, J., Do, L., Gorospe, M. \& Becker, K. G. (2005) Control of gene expression during $T$ cell activation: alternate regulation of mRNA transcription and mRNA stability, BMC genomics. 6, 75.

3. Romero-Santacreu, L., Moreno, J., Perez-Ortin, J. E. \& Alepuz, P. (2009) Specific and global regulation of mRNA stability during osmotic stress in Saccharomyces cerevisiae, RNA. 15, 1110-20.

4. Castells-Roca, L., Garcia-Martinez, J., Moreno, J., Herrero, E., Belli, G. \& Perez-Ortin, J. E. (2011) Heat shock response in yeast involves changes in both transcription rates and mRNA stabilities, PLoS One. 6, e17272.

5. Matoulkova, E., Michalova, E., Vojtesek, B. \& Hrstka, R. (2012) The role of the 3' untranslated region in post-transcriptional regulation of protein expression in mammalian cells, RNA biology. 9, 563-76.

6. Schoenberg, D. R. \& Maquat, L. E. (2012) Regulation of cytoplasmic mRNA decay, Nature reviews Genetics. 13, 246-59.

7. Chen, C. Y. \& Shyu, A. B. (1995) AU-rich elements: characterization and importance in mRNA degradation, Trends in biochemical sciences. 20, 465-70.

8. Barreau, C., Paillard, L. \& Osborne, H. B. (2005) AU-rich elements and associated factors: are there unifying principles?, Nucleic Acids Res. 33, 7138-50.

9. Garneau, N. L., Wilusz, J. \& Wilusz, C. J. (2007) The highways and byways of mRNA decay, Nature reviews Molecular cell biology. 8, 113-26.

10. Collart, M. A. \& Panasenko, O. O. (2012) The Ccr4--not complex, Gene. 492, 42-53.

11. Xu, K., Bai, Y., Zhang, A., Zhang, Q. \& Bartlam, M. G. (2014) Insights into the structure and architecture of the CCR4-NOT complex, Frontiers in genetics. 5, 137.

12. Chen, C. Y. \& Shyu, A. B. (2011) Mechanisms of deadenylation-dependent decay, Wiley interdisciplinary reviews $R N A$. 2, 167-83. 
13. Blackshear, P. J. \& Perera, L. (2014) Phylogenetic distribution and evolution of the linked RNA-binding and NOT1-binding domains in the tristetraprolin family of tandem $\mathrm{CCCH}$ zinc finger proteins, $J$ Interferon Cytokine Res. 34, 297-306.

14. Carballo, E., Lai, W. S. \& Blackshear, P. J. (1998) Feedback inhibition of macrophage tumor necrosis factor-alpha production by tristetraprolin, Science. 281, 1001-5.

15. Lin, N. Y., Lin, T. Y., Yang, W. H., Wang, S. C., Wang, K. T., Su, Y. L., Jiang, Y. W., Chang, G. D. \& Chang, C. J. (2012) Differential expression and functional analysis of the tristetraprolin family during early differentiation of 3T3-L1 preadipocytes, Int J Biol Sci. 8, 761-77.

16. Lin, N. Y., Lin, C. T., Chen, Y. L. \& Chang, C. J. (2007) Regulation of tristetraprolin during differentiation of 3T3-L1 preadipocytes, FEBS J. 274, 867-78.

17. Chrestensen, C. A., Schroeder, M. J., Shabanowitz, J., Hunt, D. F., Pelo, J. W., Worthington, M. T. \& Sturgill, T. W. (2004) MAPKAP kinase 2 phosphorylates tristetraprolin on in vivo sites including Ser178, a site required for 14-3-3 binding, J Biol Chem. 279, 10176-84.

18. Stoecklin, G., Stubbs, T., Kedersha, N., Wax, S., Rigby, W. F., Blackwell, T. K. \& Anderson, P. (2004) MK2induced tristetraprolin:14-3-3 complexes prevent stress granule association and ARE-mRNA decay, EMBO J. 23, 1313-24.

19. Sun, L., Stoecklin, G., Van Way, S., Hinkovska-Galcheva, V., Guo, R. F., Anderson, P. \& Shanley, T. P. (2007) Tristetraprolin (TTP)-14-3-3 complex formation protects TTP from dephosphorylation by protein phosphatase $2 \mathrm{a}$ and stabilizes tumor necrosis factor-alpha mRNA, J Biol Chem. 282, 376677.

20. Rahman, M. M., Rumzhum, N. N., Morris, J. C., Clark, A. R., Verrills, N. M. \& Ammit, A. J. (2015) Basal protein phosphatase $2 \mathrm{~A}$ activity restrains cytokine expression: role for MAPKs and tristetraprolin, Sci Rep. 5, 10063.

21. Wang, K. T., Wang, H. H., Wu, Y. Y., Su, Y. L., Chiang, P. Y., Lin, N. Y., Wang, S. C., Chang, G. D. \& Chang, C. J. (2015) Functional regulation of Zfp36l1 and Zfp36l2 in response to lipopolysaccharide in mouse RAW264.7 macrophages, J Inflamm (Lond). 12, 42.

22. Ross, E. A., Smallie, T., Ding, Q., O'Neil, J. D., Cunliffe, H. E., Tang, T., Rosner, D. R., Klevernic, I., Morrice, N. A., Monaco, C., Cunningham, A. F., Buckley, C. D., Saklatvala, J., Dean, J. L. \& Clark, A. R. (2015) Dominant Suppression of Inflammation via Targeted Mutation of the mRNA Destabilizing Protein Tristetraprolin, J Immunol. 195, 265-76.

23. Fabian, M. R., Frank, F., Rouya, C., Siddiqui, N., Lai, W. S., Karetnikov, A., Blackshear, P. J., Nagar, B. \& Sonenberg, N. (2013) Structural basis for the recruitment of the human CCR4-NOT deadenylase complex by tristetraprolin, Nat Struct Mol Biol. 20, 735-9.

24. Sandler, H., Kreth, J., Timmers, H. T. \& Stoecklin, G. (2011) Not1 mediates recruitment of the deadenylase Caf1 to mRNAs targeted for degradation by tristetraprolin, Nucleic Acids Res. 39, 437386.

25. Marchese, F. P., Aubareda, A., Tudor, C., Saklatvala, J., Clark, A. R. \& Dean, J. L. MAPKAP kinase 2 blocks tristetraprolin-directed mRNA decay by inhibiting CAF1 deadenylase recruitment, J Biol Chem. 
$285,27590-600$.

26. Clement, S. L., Scheckel, C., Stoecklin, G. \& Lykke-Andersen, J. (2011) Phosphorylation of tristetraprolin by MK2 impairs AU-rich element mRNA decay by preventing deadenylase recruitment, Mol Cell Biol. 31, 256-66.

27. Brook, M., Tchen, C. R., Santalucia, T., Mcllrath, J., Arthur, J. S., Saklatvala, J. \& Clark, A. R. (2006) Posttranslational regulation of tristetraprolin subcellular localization and protein stability by p38 mitogen-activated protein kinase and extracellular signal-regulated kinase pathways, Mol Cell Biol. 26, 2408-18.

28. Deleault, K. M., Skinner, S. J. \& Brooks, S. A. (2008) Tristetraprolin regulates TNF TNF-alpha mRNA stability via a proteasome dependent mechanism involving the combined action of the ERK and p38 pathways, Mol Immunol. 45, 13-24.

29. Su, Y. L., Wang, S. C., Chiang, P. Y., Lin, N. Y., Shen, Y. F., Chang, G. D. \& Chang, C. J. (2012) Tristetraprolin inhibits poly(A)-tail synthesis in nuclear mRNA that contains AU-rich elements by interacting with poly(A)-binding protein nuclear 1, PLoS One. 7, e41313.

30. Doench, J. G., Fusi, N., Sullender, M., Hegde, M., Vaimberg, E. W., Donovan, K. F., Smith, I., Tothova, Z., Wilen, C., Orchard, R., Virgin, H. W., Listgarten, J. \& Root, D. E. (2016) Optimized sgRNA design to maximize activity and minimize off-target effects of CRISPR-Cas9, Nature biotechnology. 34, 184191.

31. Chen, B., Gilbert, L. A., Cimini, B. A., Schnitzbauer, J., Zhang, W., Li, G. W., Park, J., Blackburn, E. H., Weissman, J. S., Qi, L. S. \& Huang, B. (2013) Dynamic imaging of genomic loci in living human cells by an optimized CRISPR/Cas system, Cell. 155, 1479-91.

32. Lin, S., Staahl, B. T., Alla, R. K. \& Doudna, J. A. (2014) Enhanced homology-directed human genome engineering by controlled timing of CRISPR/Cas9 delivery, Elife. 3, e04766.

33. Adachi, S., Homoto, M., Tanaka, R., Hioki, Y., Murakami, H., Suga, H., Matsumoto, M., Nakayama, K. I., Hatta, T., lemura, S. \& Natsume, T. (2014) ZFP36L1 and ZFP36L2 control LDLR mRNA stability via the ERK-RSK pathway, Nucleic Acids Res. 42, 10037-49.

34. Arencibia, J. M., Pastor-Flores, D., Bauer, A. F., Schulze, J. O. \& Biondi, R. M. (2013) AGC protein kinases: from structural mechanism of regulation to allosteric drug development for the treatment of human diseases, Biochimica et biophysica acta. 1834, 1302-21.

35. Chen, Y. L., Huang, Y. L., Lin, N. Y., Chen, H. C., Chiu, W. C. \& Chang, C. J. (2006) Differential regulation of ARE-mediated TNFalpha and IL-1 beta mRNA stability by lipopolysaccharide in RAW264.7 cells, Biochem Biophys Res Commun. 346, 160-8.

36. Taylor, G. A., Thompson, M. J., Lai, W. S. \& Blackshear, P. J. (1996) Mitogens stimulate the rapid nuclear to cytosolic translocation of tristetraprolin, a potential zinc-finger transcription factor, $\mathrm{Mol}$ Endocrinol. 10, 140-6.

37. Phillips, R. S., Ramos, S. B. \& Blackshear, P. J. (2002) Members of the tristetraprolin family of tandem $\mathrm{CCCH}$ zinc finger proteins exhibit CRM1-dependent nucleocytoplasmic shuttling, J Biol Chem. 277, 11606-13. 
38. Sandler, H. \& Stoecklin, G. (2008) Control of mRNA decay by phosphorylation of tristetraprolin, Biochem Soc Trans. 36, 491-6.

39. Clark, A. R. \& Dean, J. L. (2016) The control of inflammation via the phosphorylation and dephosphorylation of tristetraprolin: a tale of two phosphatases, Biochem Soc Trans. 44, 1321-1337.

40. Tiedje, C., Kotlyarov, A. \& Gaestel, M. (2010) Molecular mechanisms of phosphorylation-regulated TTP (tristetraprolin) action and screening for further TTP-interacting proteins, Biochem Soc Trans. 38, 1632-7.

41. Petit, A. P., Wohlbold, L., Bawankar, P., Huntzinger, E., Schmidt, S., Izaurralde, E. \& Weichenrieder, O. (2012) The structural basis for the interaction between the CAF1 nuclease and the NOT1 scaffold of the human CCR4-NOT deadenylase complex, Nucleic Acids Res. 40, 11058-72.

42. Chen, Y., Boland, A., Kuzuoglu-Ozturk, D., Bawankar, P., Loh, B., Chang, C. T., Weichenrieder, O. \& Izaurralde, E. (2014) A DDX6-CNOT1 complex and W-binding pockets in CNOT9 reveal direct links between miRNA target recognition and silencing, Molecular cell. 54, 737-50.

43. Mathys, H., Basquin, J., Ozgur, S., Czarnocki-Cieciura, M., Bonneau, F., Aartse, A., Dziembowski, A., Nowotny, M., Conti, E. \& Filipowicz, W. (2014) Structural and biochemical insights to the role of the CCR4-NOT complex and DDX6 ATPase in microRNA repression, Molecular cell. 54, 751-65.

44. Boland, A., Chen, Y., Raisch, T., Jonas, S., Kuzuoglu-Ozturk, D., Wohlbold, L., Weichenrieder, O. \& Izaurralde, E. (2013) Structure and assembly of the NOT module of the human CCR4-NOT complex, Nature structural \& molecular biology. 20, 1289-97.

45. Bhaskar, V., Roudko, V., Basquin, J., Sharma, K., Urlaub, H., Seraphin, B. \& Conti, E. (2013) Structure and RNA-binding properties of the Not1-Not2-Not5 module of the yeast Ccr4-Not complex, Nature structural \& molecular biology. 20, 1281-8.

46. Mauxion, F., Preve, B. \& Seraphin, B. (2013) C2ORF29/CNOT11 and CNOT10 form a new module of the CCR4-NOT complex, RNA biology. 10, 267-76.

47. Basquin, J., Roudko, V. V., Rode, M., Basquin, C., Seraphin, B. \& Conti, E. (2012) Architecture of the nuclease module of the yeast Ccr4-not complex: the Not1-Caf1-Ccr4 interaction, Molecular cell. 48, 207-18.

48. Rouya, C., Siddiqui, N., Morita, M., Duchaine, T. F., Fabian, M. R. \& Sonenberg, N. (2014) Human DDX6 effects miRNA-mediated gene silencing via direct binding to CNOT1, RNA. 20, 1398-409.

49. Qi, M. Y., Wang, Z. Z., Zhang, Z., Shao, Q., Zeng, A., Li, X. Q., Li, W. Q., Wang, C., Tian, F. J., Li, Q., Zou, J., Qin, Y. W., Brewer, G., Huang, S. \& Jing, Q. (2012) AU-rich-element-dependent translation repression requires the cooperation of tristetraprolin and RCK/P54, Mol Cell Biol. 32, 913-28.

50. O'Neil, J. D., Ammit, A. J. \& Clark, A. R. (2018) MAPK p38 regulates inflammatory gene expression via tristetraprolin: Doing good by stealth, Int J Biochem Cell Biol. 94, 6-9.

51. Hitti, E., lakovleva, T., Brook, M., Deppenmeier, S., Gruber, A. D., Radzioch, D., Clark, A. R., Blackshear, P. J., Kotlyarov, A. \& Gaestel, M. (2006) Mitogen-activated protein kinase-activated protein kinase 2 regulates tumor necrosis factor mRNA stability and translation mainly by altering tristetraprolin expression, stability, and binding to adenine/uridine-rich element, Mol Cell Biol. 26, 2399-407. 
52. Ngoc, L. V., Wauquier, C., Soin, R., Bousbata, S., Twyffels, L., Kruys, V. \& Gueydan, C. (2014) Rapid proteasomal degradation of posttranscriptional regulators of the TIS11/tristetraprolin family is induced by an intrinsically unstructured region independently of ubiquitination, Mol Cell Biol. 34, 4315-28.

\section{Figures}
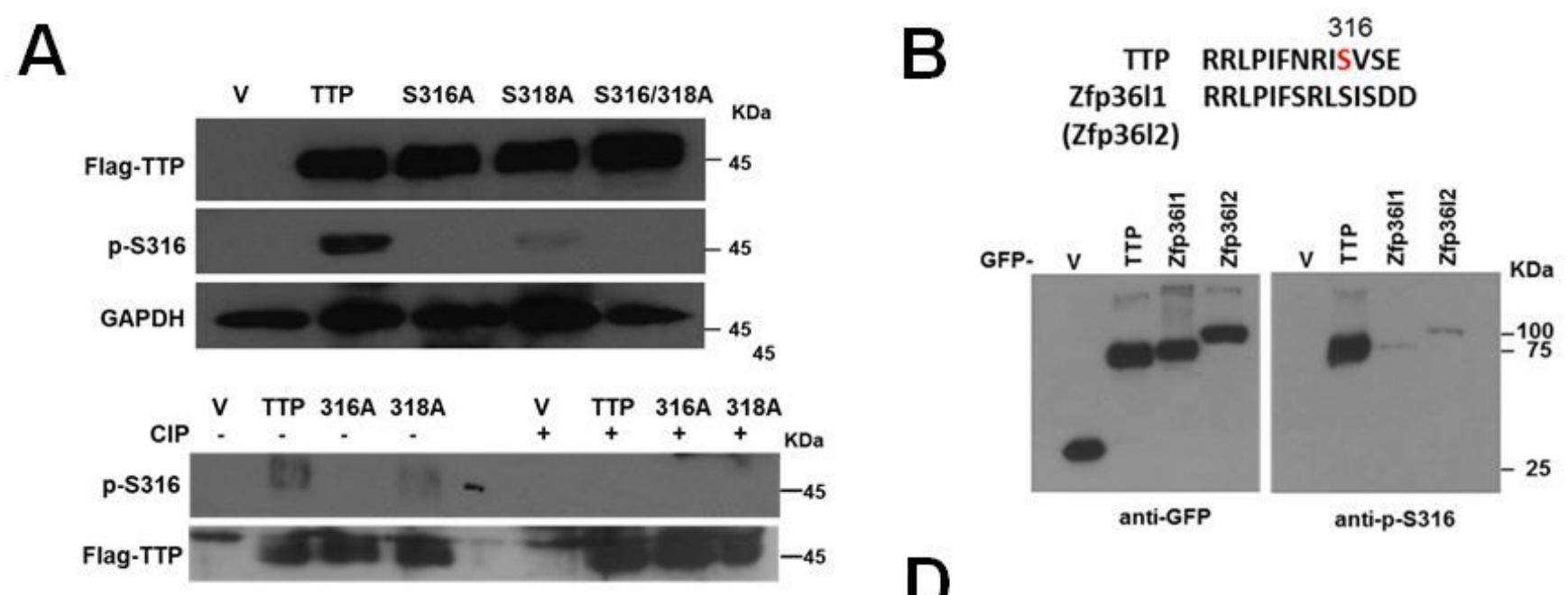

D
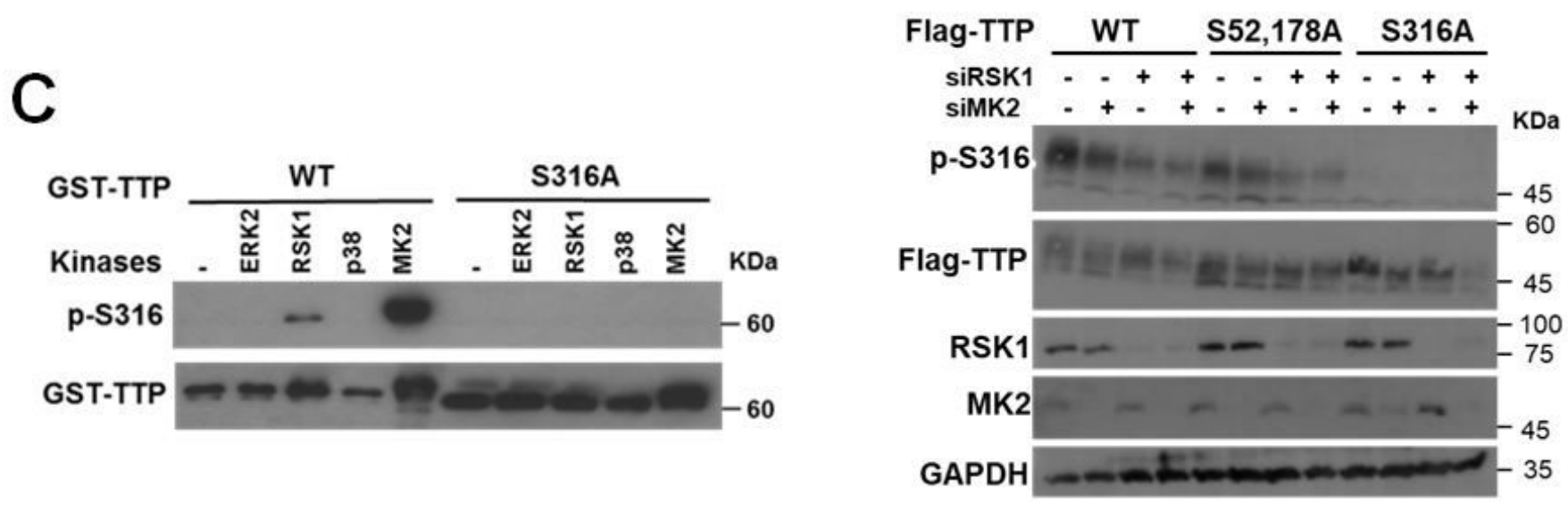

\section{Figure 1}

Generation of a specific antibody against phosphor-Ser316 of TTP. (A) The antibody specifically recognized phosphor-Ser316. 293T cells were overexpressed with wild-type, or S316A, or S318A of FlagTTP. Cell extracts were isolated and with or without alkalin phosphatase treatment for western blotting analysis by using anti-TTP, anti-phospho-S316, and anti-Flag. (B) The antibody was specific for TTP not for Zfp36l1 and Zfp3612. 293T cells were transfected with pEGFP vector (V) or EGFP-fused TTP family, TTP, Zfp36I1 or Zfp36I2, cell extracts were western blotting with anti-phospho-S316 and anti-GFP. (C) In vitro kinase assay. Recombinant GST-TTP(WT) or GST-TTP(S316A) was incubated with recombinant active kinases as indicated and then subjected to SDS-PAGE for western blotting by using anti-p-S316 
and anti-TTP. (D) Knockdown of MK2 or RSK1 decreases Ser316 phosphorylation. 293T cells were transfected with siRNA of MK2 or RSK1 for $24 \mathrm{~h}$ and then overexpressed with Flag-TTP wild-type, S316A or S52, 178A. Cell extracts were harvested for western blotting analysis by anti-phospho-S316 and antiFlag. All experiments were reproduced at least three times and the representative results were displayed.
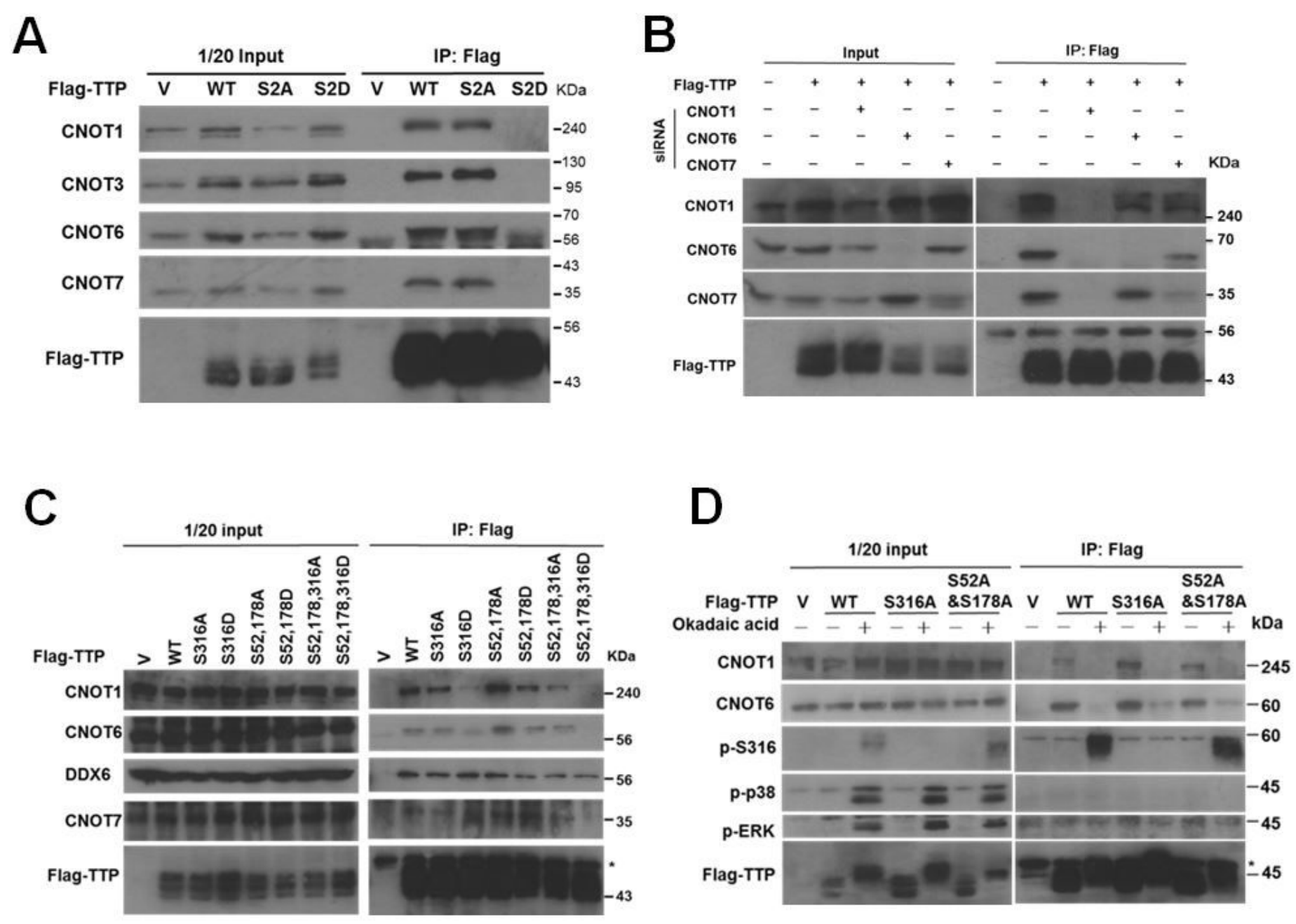

\section{Figure 2}

Ser316 phosphorylation decreases interaction with CNOT1 complex and suppresses TTP activity. (A) Immunoprecipitation analysis. 293T cells were transfected with indicated Flag-TTP constructs and whole cell extracts were immunoprecipitated by anti-Flag. The precipitated protein complexes were analyzed by western blotting with antibodies against CCR4-NOT complex as indicated. (B) TTP directly interacts with CNOT1. 293T cells were transfected with siRNA specific for CNOT1, CNOT6, or CNOT7 or a negativecontrol siRNA (NC). After $24 \mathrm{~h}$, cells were transfected again with the Flag-TTP plasmid. IP was performed with anti-Flag agarose, and precipitated protein complexes were detected with antibodies against CNOT1, CNOT6, CNOT7, and Flag. (C) Immunoprecipitation analysis. 293T cells were transfected with indicated Flag-TTP constructs and whole cell extracts were immunoprecipitated by anti-Flag. The precipitated protein complexes were analyzed by western blotting with indicated antibodies. (D) 293T cells were 
transfected with WT, S316A, or S52,178A Flag-TTP and treated with or without $1 \mu \mathrm{M}$ of okadaic acid (OA) for $1 \mathrm{~h}$. Whole cell extracts were immunoprecipitated with anti-Flag and western blotting with indicated antibodies.

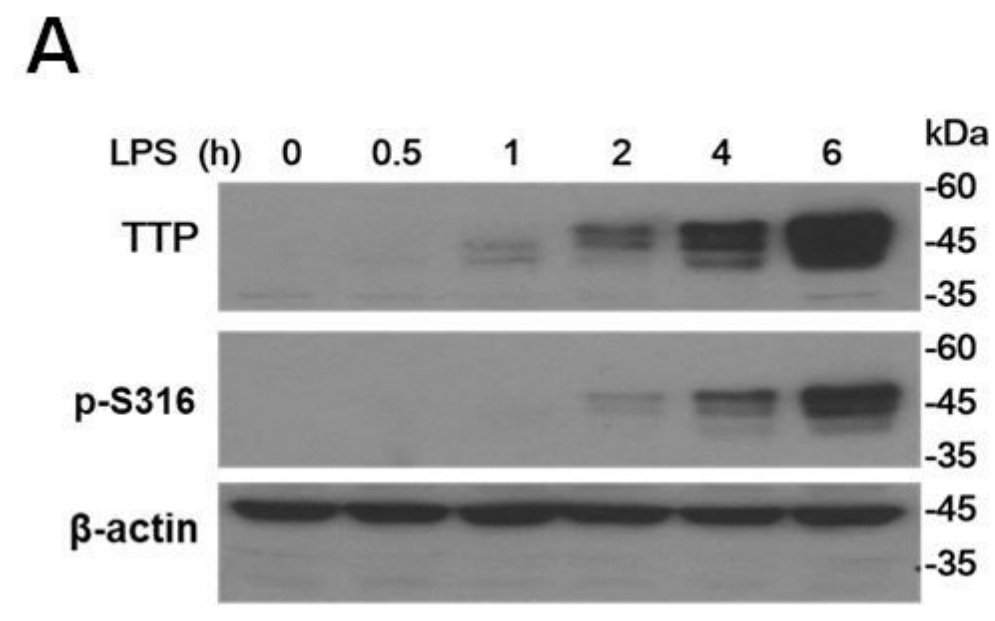

C

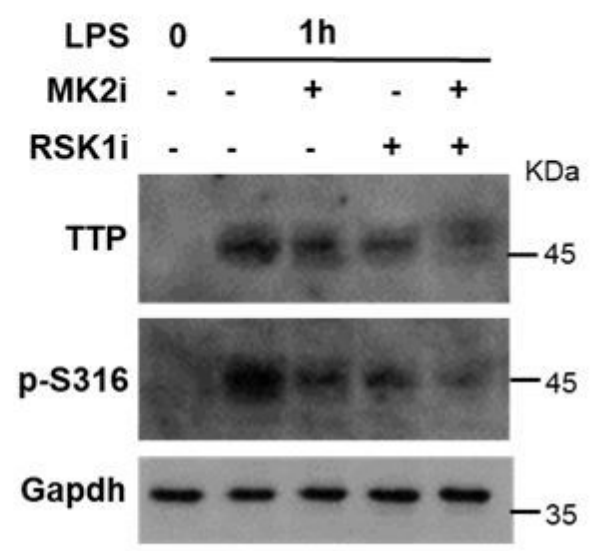

D

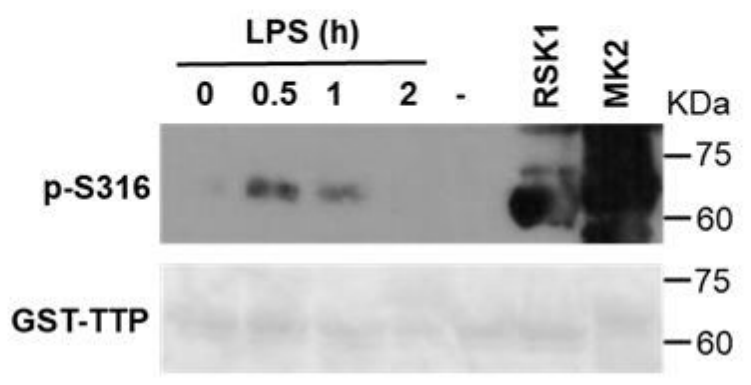

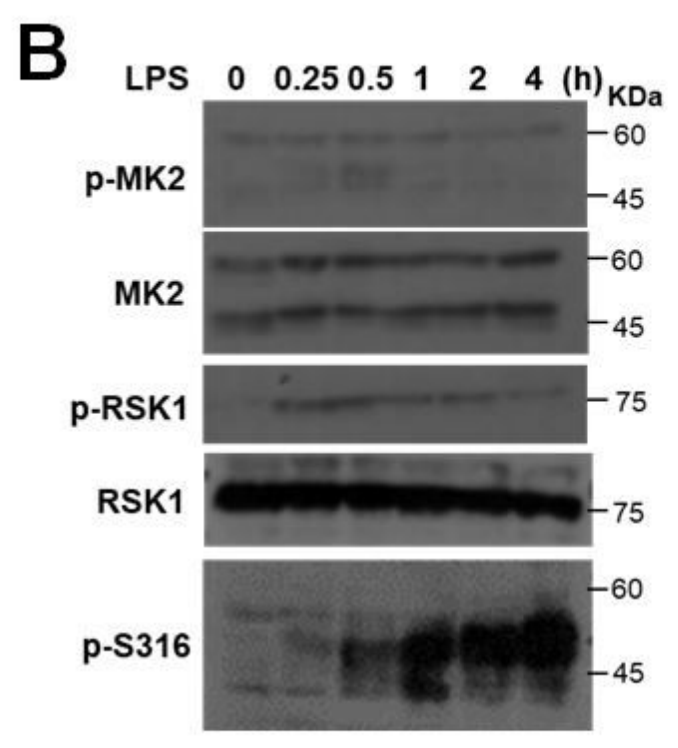

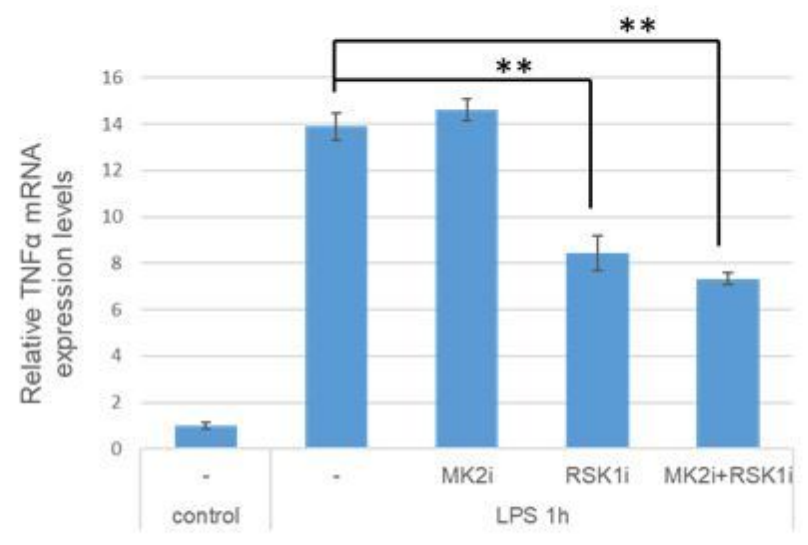

\section{Figure 3}

Ser316 is phosphorylated in LPS-treated RAW264.7 cells. (A) Kinetic analysis of Ser316 phosphorylation. RAW264.7 cells were treated with $100 \mathrm{ng} / \mathrm{ml}$ of LPS for indicated time intervals. Whole cell extracts were isolated for western blotting analysis as indicated. (B) Whole cell extracts were isolated and western blotting analysis with antibodies as indicated. (C) RAW264.7 cells were pretreated with $2 \mu \mathrm{M}$ of MK2 or $25 \mu \mathrm{M}$ of RSK 1 inhibitors for $0.5 \mathrm{~h}$ and followed by LPS stimulation for $1 \mathrm{~h}$. Whole cell extracts were 
isolated and western blotting analysis with antibodies as indicated, and RNA was isolated for RT-qPCR with control $\beta$-actin and TNFa primers. (D) Solid phase kinase assay. GST-TTP bound on glutathione sepharose was incubated with or without LPS-treated cell lysates. After extensive washes, kinase assays were performed. RSK1 and MK2 were included as positive control. The samples were separated on SDSPAGE and western blotting with anti-p-S316 and then poncean S staining.
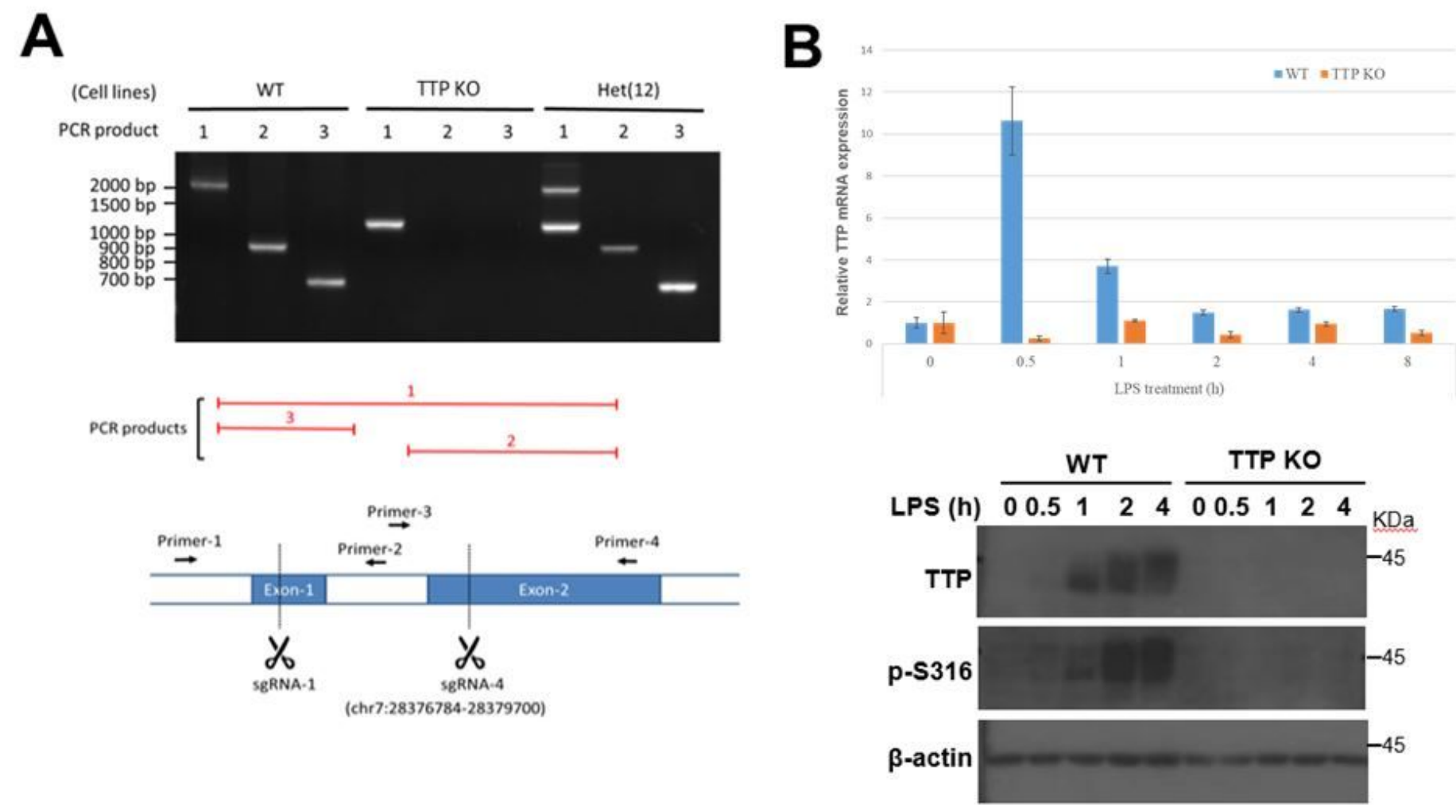

\section{Figure 4}

Generation of TTP knockout RAW264.7 cells. (A) The homozygous and heterozygous KO cells were generated by double breaks of CRISPR/Cas 9 genome editing in mouse RAW264.7 cells. (B) TTP mRNA and protein expression in LPS-stimulated wild-type and TTP KO cells. 
A

\section{$T N F a$}

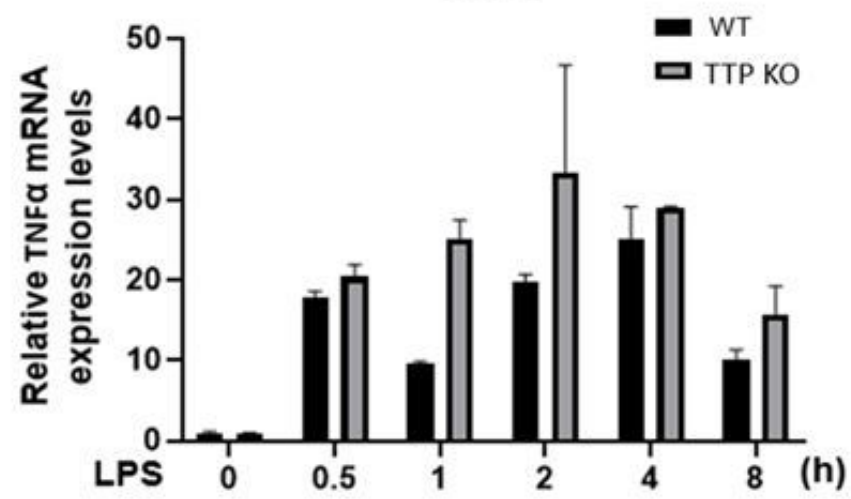

B

$T N F \alpha$

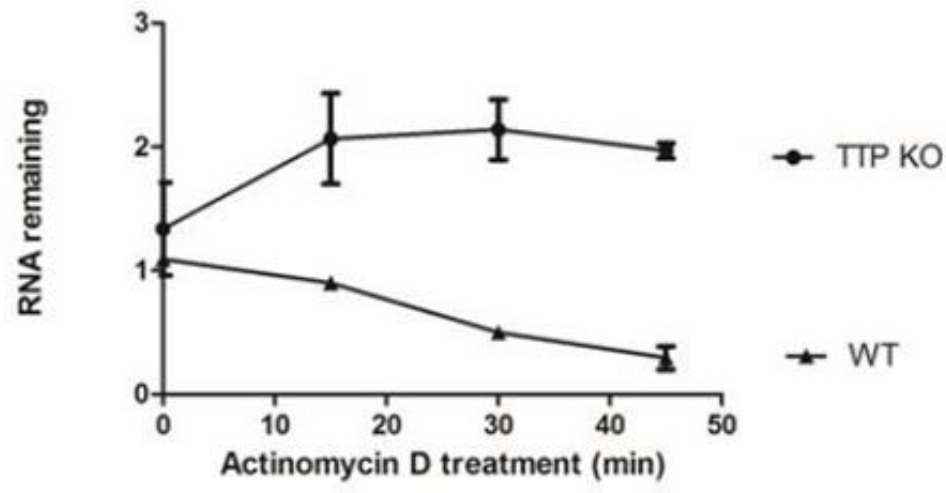

C

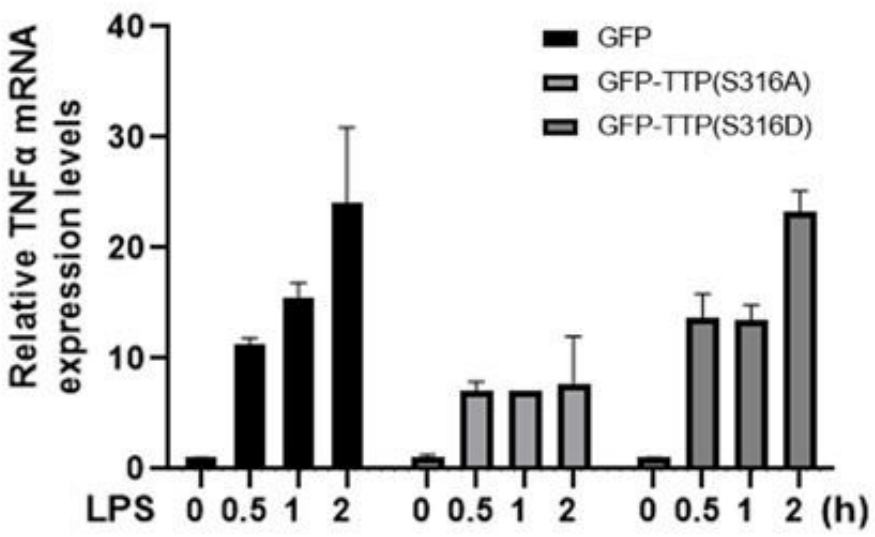

Figure 5

Functional analysis of Ser316 phosphorylation in LPS-stimulated RAW264.7 cells. (A) Kinetics of TNFa mRNA expression in LPS-treated wild-type and TTP KO cells. (B) TNFa mRNA stability analysis. Wild-type and TTP KO RAW264.7 cells were treated with $100 \mathrm{ng} / \mathrm{ml}$ of LPS for $30 \mathrm{~min}$ and then adding $10 \mu \mathrm{g} / \mathrm{ml}$ of actinomycin $D$ to block transcription for 15,30 and $45 \mathrm{~min}$. Total RNAs were isolated to perform RT-qPCR. (C) TTP rescue analysis. TTP KO cells were transfected with vector, GFP-TTP(WT), or GFP-TTP(S316A), or 
GFP-TTP(S316D). After $24 \mathrm{~h}$, the cells were treated with $100 \mathrm{ng} / \mathrm{ml}$ of LPS for $30 \mathrm{~min}$ and followed by adding $10 \mu \mathrm{g} / \mathrm{ml}$ actinomycin $D$ for $0,15,30$, and $45 \mathrm{~min}$. RNA was isolated for qPCR analysis with TNFa and $\beta$-actin primer and the percent of RNA remaining was shown. All experiments were performed independently at least three times, and error bars represent mean \pm S.E.
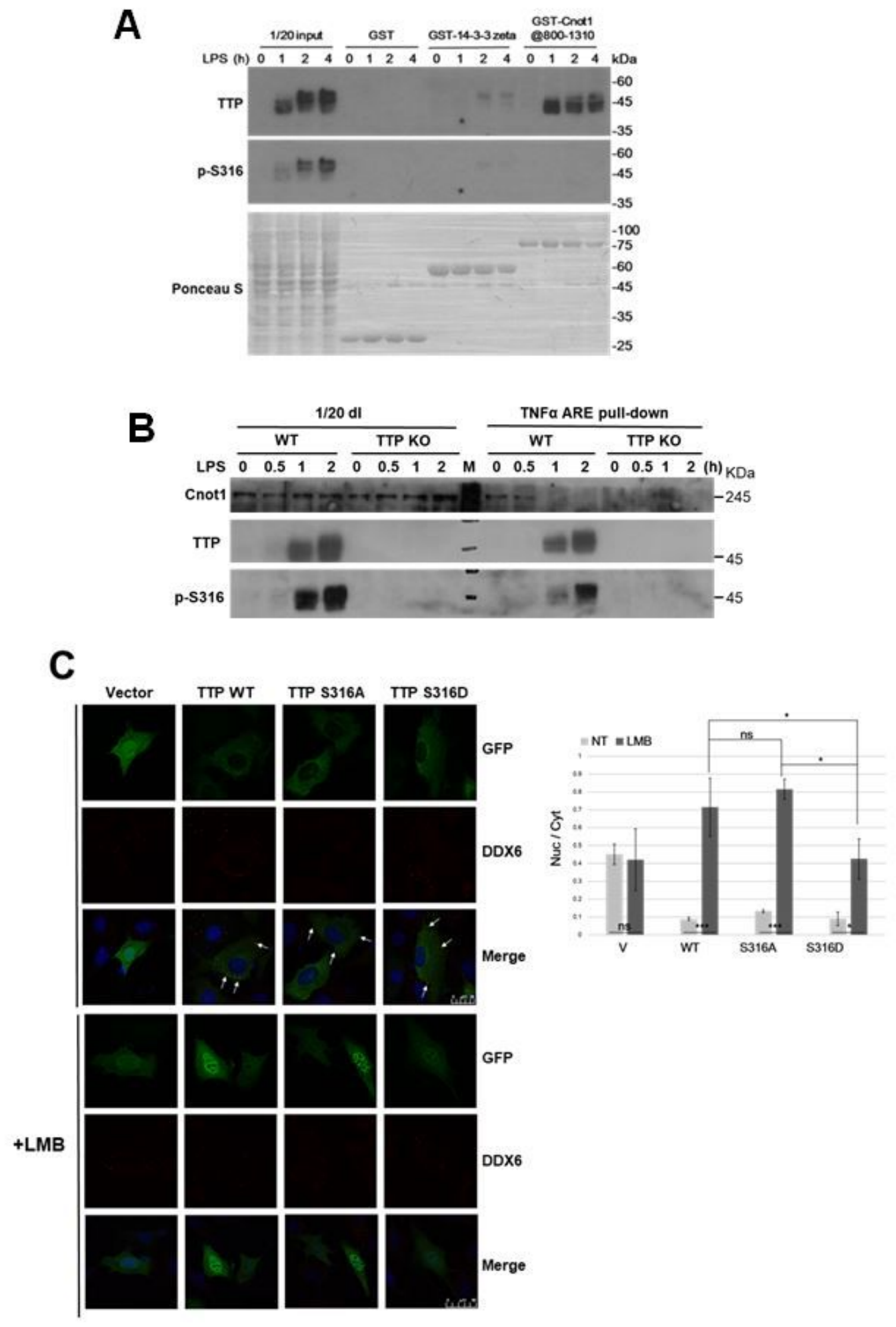

Figure 6 
Ser316 phosphorylation impairs TTP interaction with CNOT1 in LPS-stimulated RAW264.7 cells. (A) GSTpull down assay. RAW264.7 cells were treated with $100 \mathrm{ng} / \mathrm{ml}$ LPS for $0,1,2$, and $4 \mathrm{~h}$. Whole cell extracts were harvested and incubated with GSH sepharase-bound GST, or GST-14-3-3, or GST-Cnot1@800-1310. The pulled down protein complexes were analyzed by western blotting with anti-TTP and anti-p-S316 antibodies. (B) RNA pull-down assay. TNFa ARE probe was incubated with cell extracts from control and LPS-treated for $0.5 \mathrm{~h}, 1 \mathrm{~h}$ and $2 \mathrm{~h}$. The pull-down RNA-protein complexes were analyzed by western blotting with anti-TTP, anti-phospho-S316, and anti-Cnot1. (C) Immunofluorescent staining. NIH3T3 cells cultured on cover slips were transfected with GFP, GFP-TTP(WT), GFP-TTP S316A, or GFP-TTP S316D expressing plasmids. After $24 \mathrm{~h}$, the cells were untreated (control) or treated with leptomycin $B(L M B)$ for $5 \mathrm{~h}$. Immunofluorescence was performed using anti-DDX6 as a marker of p-bodies and images were recorded using confocal microscope. The arrows indicate the association of GFP and DDX6 signals. The size bar in control panel is $25 \mu \mathrm{M}$ and in LMB panel is $50 \mu \mathrm{M}$. Right panel was the quantitative immunofluorescence analysis showing the ratio of nuclear and cytoplasm signals. At least three independent experiments were performed.

\section{Supplementary Files}

This is a list of supplementary files associated with this preprint. Click to download.

- Supplementryfile1.doc 